Case report

\title{
A case series of reflex myoclonic absence epilepsy of infancy - an age-dependent idiopathic generalized epileptic (IGE) syndrome - with good prognosis
}

\author{
Umesh Kalane* , Shilpa Kalane \\ Department of Pediatrics, Deenanath Mangeshkar Hospital, Pune, India
}

\section{A R T I C L E I N F O}

\section{Article history:}

Received 29 November 2015

Accepted 11 July 2016

Available online 17 October 2016

\section{Keywords:}

RMEI

MEI

Reflex myoclonic epilepsy of infancy

\begin{abstract}
A B S T R A C T
Background: Myoclonic epilepsies in the infantile age have varied presentations including benign myoclonic epilepsy of infancy (MEI) on one side and Doose, west, Dravet syndrome as well as recognized syndromes on the severe spectrum on the other side. MEI is an idiopathic disorder characterized by spontaneous myoclonic attacks with onset in the first 2 years of life. Reflex myoclonic epilepsy of infancy (RMEI) has startle- and tectile-induced myoclonias and needs distinct consideration from MEI.

Results: Hereby, a case series of 3 infants, started with reflex myoclonic absence seizures before 12 months of age, has been described. All the infants have unremarkable birth history, normal development, and examination. They started with myoclonic jerks involving torso and upper extremities and were associated with startle induced by unexpected sounds and tectile stimulation. All children were treated with valproate and were followed till date with minimum follow-up of 12 months and showed complete seizure control at low dose of valproate. At 6-month follow-up, all children were seizure-free with normal development.

Conclusion: Reflex myoclonic absence epilepsy is an age-dependent idiopathic generalized epileptic (IGE) syndrome, with an apparently good prognosis. It needs to be recognized separately as new syndrome and should be differentiated from the other myoclonic epilepsies of same age.

(c) 2016 Indian Epilepsy Society. Published by Elsevier, a division of RELX India, Pvt. Ltd. All rights reserved.
\end{abstract}

\section{Case reports}

\subsection{Case no. 1}

A previously healthy 10-month-old girl, the only child of unrelated parents, presented with a four-week history of episodes of myoclonus triggered by tactile stimulation to her head and also by loud, sudden acoustic stimulation. Birth history was uneventful and the child achieved milestones at appropriate age. There had been no loss of developmental skills. The video electroencephalogram (EEG) revealed brief generalized polyspike wave activity at 2.5-3 Hz both with and without clinical correlate provoked with stimulation, suggesting reflex myoclonic absences (Fig. 1) (video 1 ). Neuroimaging study with magnetic resonance imaging (MRI

\footnotetext{
* Corresponding author at: Flat no.202, G building, Wonder City Society, Katraz Serve No 75, Pune 411046, Maharashtra, India.

Tel.: +91 9324316759/02024430602.

E-mail address: umeshkalane@yahoo.com (U. Kalane).
}

$1.5 \mathrm{~T}$ ) was within normal limits. Karyotyping showed normal female phenotype (46XY). Cerebrospinal fluid study yielded normal sugar and lactate levels. The infant was started on sodium valproate, which resulted in cessation of the myoclonic episodes one week after starting therapy. At subsequent follow-up after 6 months of initiation of treatment, the infant was seizure-free and a repeat EEG was normal. Valproate was tapered and omitted. Follow-up at 2 years of age showed that child is seizure-free and with normal development.

\subsection{Case no. 2}

A 1-year-old boy was presented for the evaluation of myoclonic jerks since previous one week. He had normal examination with no significant birth or family history and with normal developmental milestones. Myoclonic jerks were elicited with sudden loud noise and associated with rhythmic shoulder jerking with uprolling of eyes briefly. Video electroencephalograph captured few events with shoulder jerking and eyes upturned with simultaneous ictal generalized discharges of high amplitude spike-wave at $3 \mathrm{~Hz}$ 


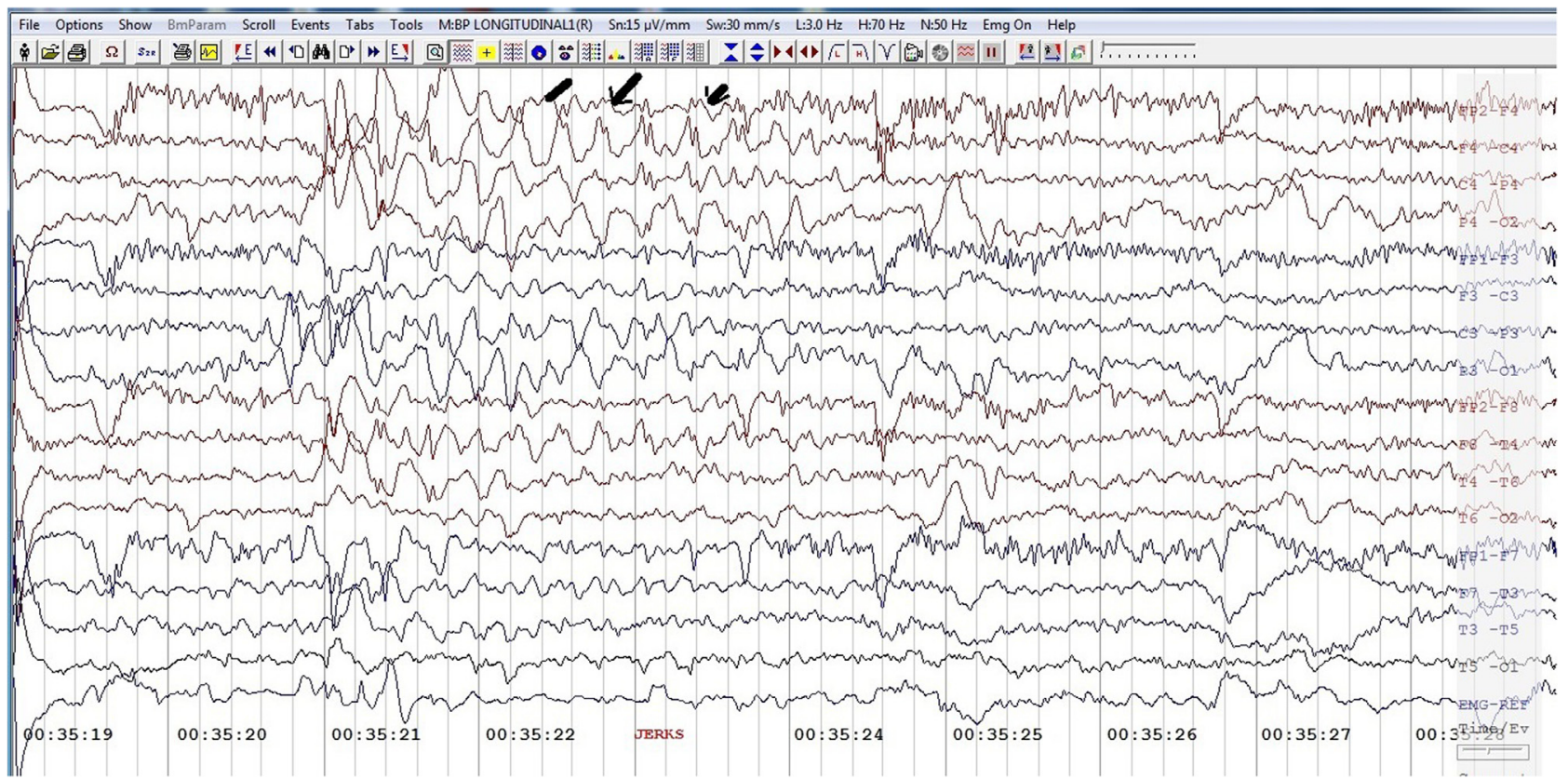

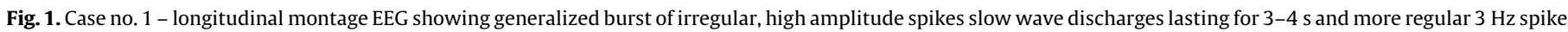
wave discharges toward the end (black arrows). Paper speed $30 \mathrm{~mm} / \mathrm{s}$, sensitivity $15 \mu \mathrm{V} / \mathrm{mm}$.

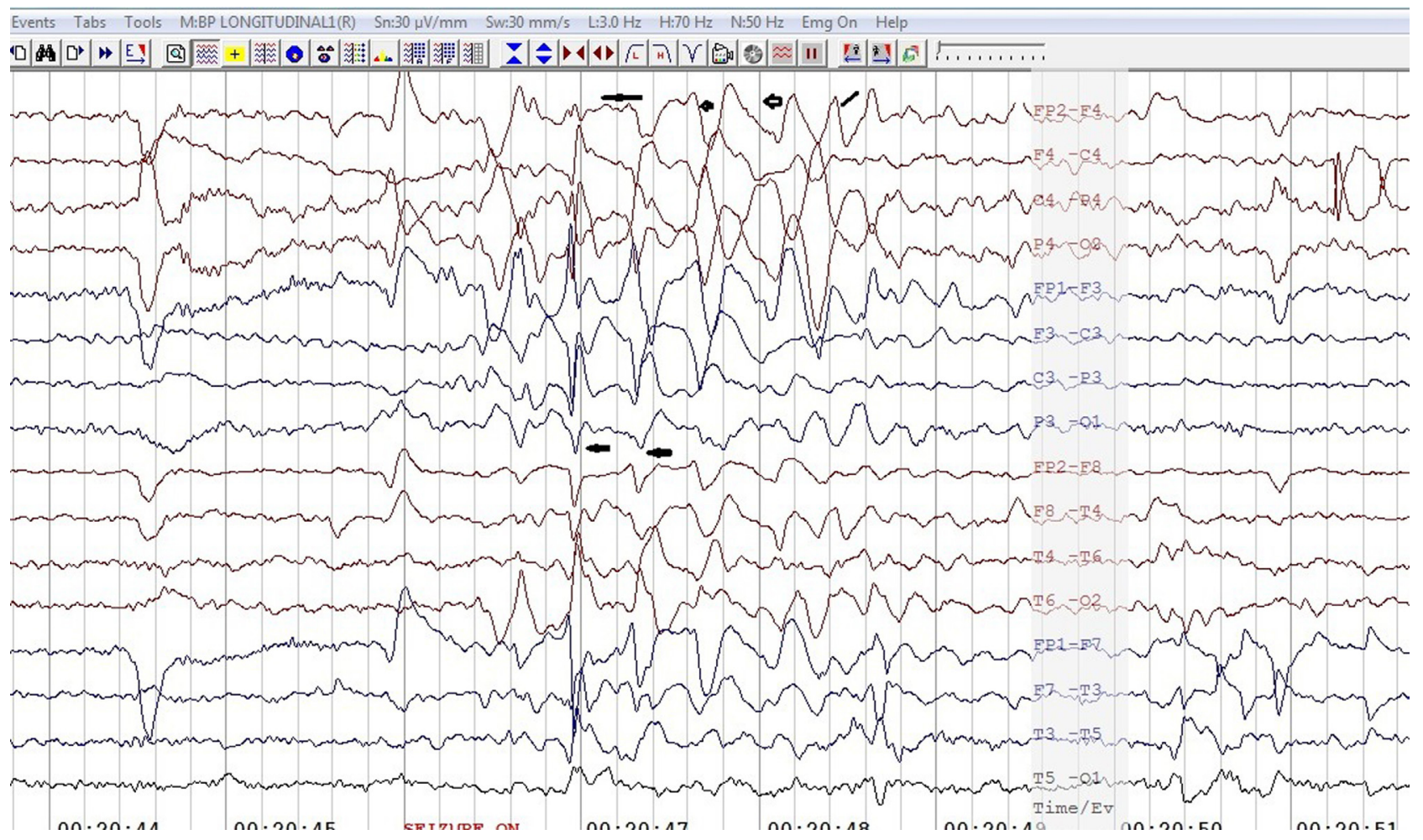

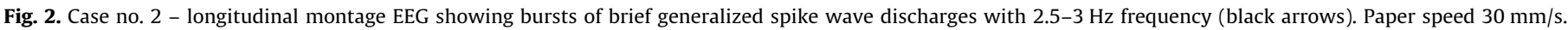
Sensitivity $30 \mu \mathrm{V} / \mathrm{mm}$.

lasting for 1-3 s (Fig. 2) (video 2). A diagnosis of reflex myoclonic epilepsy of infancy was made. MRI brain was normal. Parents refused CSF studies. The patient was started on low dose valproate $(15 \mathrm{mg} / \mathrm{kg} / \mathrm{day})$ with gradual step-up. Seizures ceased in few days of initiation of treatment. A repeat EEG after 6 months was normal and valproate was gradually tapered and omitted. He had normal examination and development at follow-up at the age of 2.5 years.

\subsection{Case no. 3}

Similar to above cases, a 1-year-old girl was presented for onset of startle-induced myoclonias since last few days. She did not have spontaneous myoclonias. She has normal birth history and development with no family history of seizures. Electroencephalography showed interictal polyspike-wave discharges with 
Table 1

Summary of details of cases.

\begin{tabular}{|c|c|c|c|c|c|c|c|c|c|c|c|c|}
\hline $\begin{array}{l}\text { Case } \\
\text { no. }\end{array}$ & $\begin{array}{l}\text { Age } \\
\text { onset }\end{array}$ & Sex & $\begin{array}{l}\text { Family } \\
\text { hist. }\end{array}$ & $\begin{array}{l}\text { Trigger } \\
\text { stimuli }\end{array}$ & $\begin{array}{l}\text { Spontaneous } \\
\text { jerks }\end{array}$ & $\begin{array}{l}\text { Ictal } \\
\text { EEG }\end{array}$ & $\begin{array}{l}\text { Interictal } \\
\text { EEG }\end{array}$ & Investigations & AED & $\begin{array}{l}\text { Treatment } \\
\text { duration }\end{array}$ & $\begin{array}{l}\text { FOP } \\
\text { in years }\end{array}$ & $\begin{array}{l}\text { Pyschomotor } \\
\text { development }\end{array}$ \\
\hline 1 & 9 month & $\mathrm{F}$ & Nil & $\begin{array}{l}\text { Startle and } \\
\text { tectile }\end{array}$ & Present & $\begin{array}{l}\text { Brief } 3 \mathrm{~Hz} \\
\text { GSWD }\end{array}$ & $\begin{array}{l}\text { Irregular } \\
\text { GSWD }\end{array}$ & $\begin{array}{l}\text { MRI brain N, } \\
\text { karyotyping } N, \text { CSF N }\end{array}$ & VPA & 6 month & 2 years of age & Normal \\
\hline 2 & 12 month & M & Nil & $\begin{array}{l}\text { Startle and } \\
\text { tectile }\end{array}$ & Present & $\begin{array}{l}\text { Brief } 3 \mathrm{~Hz} \\
\text { GSWD }\end{array}$ & $\begin{array}{l}\text { Irregular } \\
\text { GSPWD }\end{array}$ & MRI brain $\mathrm{N}$ & VPA & 6 month & 2.5 years of age & Normal \\
\hline 3 & 12 month & $\mathrm{F}$ & Nil & $\begin{array}{l}\text { Startle and } \\
\text { tectile }\end{array}$ & Absent & $\begin{array}{l}\text { Brief } 3 \mathrm{~Hz} \\
\text { GSWD }\end{array}$ & Normal & $\begin{array}{l}\text { No other } \\
\text { investigations }\end{array}$ & VPA & 6 month & 2 years of age & Normal \\
\hline
\end{tabular}

normal background, at times with frequency of 2.5-3 Hz lasting for $1 \mathrm{~s}$. With previous experience, started on valproate at low dose, she showed excellent response with complete cessation. Repeat EEG after 6 months was normal with normal development; hence valproate was omitted. Follow-up at 2 years of age showed normal age appropriate development (Table 1 - summary of all cases).

\section{Discussion}

Benign myoclonic epilepsy in infancy (BMEI) is characterized by the occurrence of myoclonic seizures (MS) in the first 3 years of life in normal infants. ${ }^{1-4}$ It has been classified among the idiopathic generalized epilepsies (IGE) in the 1989 International Classification (Commission on Classification and Terminology of the International League Against Epilepsy, 1989), and now included as myoclonic epilepsy in infancy (MEI) among the electroclinical syndromes arranged by age at onset in infancy, in the recent report of the ILAE Commission on Classification and Terminology.

Ricci et al., in 1995, described cases with "reflex MS", triggered by unexpected noise or touch and have proposed to name this clinical entity: "reflex myoclonic epilepsy in infancy - RMEI". ${ }^{6}$ Since then many case reports have been published in literature describing RMEI. ${ }^{7-9}$ RMEI may be under-described and underevaluated because of the short duration of the event, possibly misinterpreted as "excessive startle reaction" in otherwise healthy children. Verroti et al. carried out a multicenter study by collecting data of children with RMEI. ${ }^{8}$ They proposed criteria for inclusion and exclusion for diagnosis of RMEI.

All children had diagnosis based upon the following criteria: (1) symmetric myoclonic jerks, triggered by sudden unexpected tactile or acoustic stimuli; (2) onset of MS in the first 2 years of life; (3) normal pregnancies and perinatal history; (4) normal neuroradiological and metabolic investigations; (5) MS associated with an EEG discharge of generalized high-amplitude spike-wave (SW) or polyspikewave (PSW) at $3 \mathrm{~Hz}$ on normal background activity. ${ }^{6-9}$

Exclusion criteria were: (1) other seizure types (partial, tonic, tonic-clonic, atonic, asymmetric myoclonias, and atypical absences); (2) abnormal pre-, peri-, and postnatal history; (3) abnormal neurological examination; (4) abnormal psychomotor development (delay or regression); and (5) pathological findings on neuroradiological and metabolic investigations. ${ }^{6-9}$

Many authors have not supported RMEl's designation as a separate syndrome from MEI, considering a single clinical and nosographic syndrome. ${ }^{1-3}$ However, there is enough evidence from literature to differentiate these two clinical entities. Despite apparent similar findings, they differ in many ways:

(1) The most important difference is the complete absence of provoking factors in MEI and which is consistent finding in RMEI. $^{1-3,6-9}$

(2) Children with RMEI never show drop attacks that can be common in MEI. ${ }^{1-3,6-9}$

(3) Onset of seizures in RMEI is at an earlier age (9 months to 1 year in this case series) whereas mean duration of onset of MEI is at later ages. RMEI appears to have earlier onset than MEI: onset at 11 months in RMEI whereas the mean age at onset in MEI is 20 months. ${ }^{1-3,6-9}$

(4) Pharmacological treatment with VPA appears to be more effective in RMEI than in MEI. All our patients were seizure-free within weeks of initiation of treatment and were able to wean off antiepileptics after 6 months. Patients with MEI often require long-term treatment and discontinuing therapy in MEI may cause seizures to relapse. ${ }^{1-3}$

RMEI is a rare clinical entity. In this study, we clarify clinical and EEG findings with particular attention to cognitive outcome. Ricci et al. mentioned significant percentage of family history for IGE and/or febrile convulsions in first- or second-degree relatives, and the occurrence of febrile seizures in some patients, suggesting possibility of a complex genetic inheritance. In our study, no family history of seizures was noticed, although case numbers are limited.

All children were born to healthy parents after normal pregnancies and deliveries and all showed normal findings to neurological examinations. Interictal EEG showed normal background activity, with intermittent generalized discharges occurring spontaneously. Ictal EEG was characterized by generalized, brief, irregular, high-amplitude SW, and PSW discharge at $3 \mathrm{~Hz}$ activity and hence mentioned as reflex myoclonic absence epilepsy.

Clinical and EEG findings allow to differentiate RMEI from other epileptic syndromes with myoclonic manifestations (myoclonicastatic epilepsy, Dravet syndrome, intractable infantile epilepsy and neonatal myoclonic encephalopathy, West syndrome, and Lennox-Gastaut syndrome). ${ }^{7}$ Cognitive outcome with neuropsychological difficulties is present in one-third of children affected by $\mathrm{MEI}^{2,3}$ whereas patients with RMEI have an excellent cognitive outcome, as showed in our patients as well as other reports. ${ }^{6-9}$

RMEI also differs clearly from startle epilepsy, which is characterized by seizures and an excessive startle reaction to sudden stimuli that occurs across a wide age range. It arises from brain damage, particularly hypoxic ischemic pre- and perinatal lesions, which is never described with RMEI. Clinical and EEG patterns are also variable such as partial, tonic, atonic, and myoclonic seizures. Startle epilepsy is often refractory to treatment. $^{10}$

Distinctive EEG and EMG findings also differentiate RMEI from non-epileptic manifestations characterized by an excessive startle response: hyperekplexia or startle disease. It is an autosomal dominant disease characterized by exaggerated startle reflex and neonatal hypertonia. ${ }^{10}$

In conclusion, we proposed that reflex myoclonic absence epilepsy is an age-dependent idiopathic generalized epileptic (IGE) syndrome, with an apparently good prognosis. It needs to be recognized separately as a new syndrome and should be differentiated from the other myoclonic epilepsies of same age. Reflex myoclonic absence epilepsy needs syndromic recognition distinct from the myoclonic epilepsy of infancy (MEI).

\section{Funding}

None. 


\section{Conflicts of interest}

The authors have none to declare.

\section{Informed consent}

Informed consents were taken from parents of patients prior to this work.

\section{Appendix A. Supplementary data}

Supplementary data associated with this article can be found, in the online version, at doi:10.1016/j.ijep.2016.07.001.

\section{References}

1. Dravet C, Bureau M. Benign myoclonic epilepsy in infancy. In: Roger J, Bureau M, Dravet C, Genton P, Tassinari CA, Wolf P, eds. In: Epileptic Syndromes in Infancy, Childhood and Adolescence. Montrouge: John Libbey Eurotext; 2005: 73-76.
2. Mangano S, Fontana A, Spitaleri C, et al. Benign myoclonic epilepsy in infancy followed by childhood absence epilepsy. Seizure. 2011;20:727-730.

3. Auvin S, Pandit S, De Bellecize J, et al. Benign myoclonic epilepsy in infants: electroclinical features and long-term follow-up of 34 patients. Epilepsia. 2006; 47:387-393.

4. Giovanardi Rossi P, Parmeggiani A, Posar A, Santi A, Santucci M. Benign myoclonic epilepsy: long-term follow-up of 11 new cases. Brain Dev. 1997;19: 473-479.

5. Engel JA. Proposed diagnostic scheme for people with epileptic seizures and with epilepsy: report of the ILAE Task Force on classification and terminology. Epilepsia. 2001;42:1-8.

6. Ricci S, Cusmai R, Fusco L, Vigevano F. Reflex myoclonic epilepsy in infancy: a new age-dependent idiopathic epileptic syndrome related to startle reaction. Epilepsia. 1995;36:342-348.

7. Deonna T, Reflex seizures with somatosensory precipitation. Clinical and electroencephalographic patterns and differential diagnosis, with emphasis on reflex myoclonic epilepsy of infancy.Zifkin BG, Andermann F, Beaumanoir A, Rowan AJ, eds. Reflex Epilepsies and Reflex Seizures: Advances in Neurology. vol. 75. Philadelphia: Lippincott-Raven Publishers; 1998: 193-206.

8. Verrotti A, Matricardi S, Capovilla G, et al. Reflex myoclonic epilepsy in infancy: a multicenter clinical study. Epilepsy Res. 2013;103:237-244.

9. Zuberi SM, O'Regan ME. Developmental outcome in benign myoclonic epilepsy in infancy and reflex myoclonic epilepsy in infancy: a literature review and six new cases. Epilepsy Res. 2006;70S:S110-S115.

10. Yang Z, Liu X, Qin J, et al. Clinical and electrophysiological characteristics of startle epilepsy in childhood. Clin Neurophysiol. 2010;121:658-664. 